\title{
Las Casas de Ejercicios de los jesuitas en la antigua Provincia del Paraguay
}

\author{
Houses Exercises in the former \\ Jesuit Province of Paraguay
}

Carlos A. Page*

Resumen: Las Casas de Ejercicios fueron los ámbitos donde se practicaba el ministerio que ideó San Ignacio de Loyola, constituyéndose en uno de los pilares de la Compañía de Jesús. Desde un principio se necesitó de edificios especiales, aunque los mismos colegios suplieron lo que con el tiempo dieron lugar a una tipología particular en el contexto de la arquitectura colonial y específicamente de los domicilios jesuitas. Lamentablemente, en el amplio espacio geográfico propuesto, desaparecieron la mayoría de ellos. Se analiza aquí el origen y desarrollo de estos edificios en la otrora Provincia del Paraguay.

Palabras claves: Provincia Jesuítica del Paraguay, Ejercicios Espirituales, Casas de Ejercicios.

\begin{abstract}
The retreat houses were the areas where the ministry devised San Ignacio de Loyola, becoming one of the pillars of the Society of Jesus practiced. From the beginning it required special areas, though the same schools supplemented which eventually led to a particular type in the context of colonial architecture and specifically addresses the Jesuits. Unfortunately, the proposed broad geographical area, most of them disappeared. The origin and development of these buildings in the former Province of Paraguay discussed here.
\end{abstract}

Key words: Jesuit Province of Paraguay, Spiritual Exercises, Exercises houses.

\footnotetext{
* Arquitecto y Doctor en Historia. CONICET-CIECS/UNC. Argentina E-mail: capage1@ hotmail.com.
} 
Recibido: 11 de octubre de 2016

Evaluado: 3 de diciembre de 2016 


\section{Introducción}

Los Ejercicios Espirituales, como indica el P. Ruiz Jurado, es una actividad que Iñigo de Loyola conoció durante su estadía en Monserrat, a través del libro del abad García Jiménez de Cisneros (c.1455-1510) titulado "Exercitatorio de la vida spiritual", publicado en 1500. Fue indudablemente inspiración para san Ignacio, quien incluyó los "exámenes de conciencia, toda forma de orar, mental o vocal y otras actividades (indicadas en las "adiciones" y otros documentos) que sirven para disponer el alma a la búsqueda y encuentro de la voluntad de Dios". Agregándose como principio y fundamento el "vencer a sí mismo y ordenar su vida sin determinarse por afección alguna que desordenada sea" . Es decir que fueron concebidos fundamentalmente como un examen de conciencia y oración para disponer el alma a un encuentro con la voluntad de Dios. Concretamente se trata de alcanzar una vida ordenada, purificada en la perfección cristiana.

Es un libro complejo que se corona con la “contemplación para alcanzar amor". Metodológicamente fue concebido para ser practicado individualmente, en silencio y soledad durante un mes, bajo la guía de un director. Los Ejercicios Espirituales es uno de los ministerios fundamentales de la Compañía de Jesús, que se fueron mejorando a lo largo de los años y la experiencia acumulada, no solo por Ignacio, desde principalmente su estadía en Manresa hasta Roma, sino también por sus seguidores que fueron haciendo aportes a la Versio prima de 1541, aprobada y publicada en 1548 (Versio vulgata) (Fig. 1).

En los inicios, los retiros para los Ejercicios se daban individualmente en casas privadas, conventos o en colegios de la Compañía de Jesús. A medida que se multiplicaron los ejercitantes, se buscaron algunos cuartos aislados dentro de los colegios, hasta que se construyeron pabellones en los mismos destinados a este fin, como en el de Alcalá de Henares en 1553, que estaba aislado del

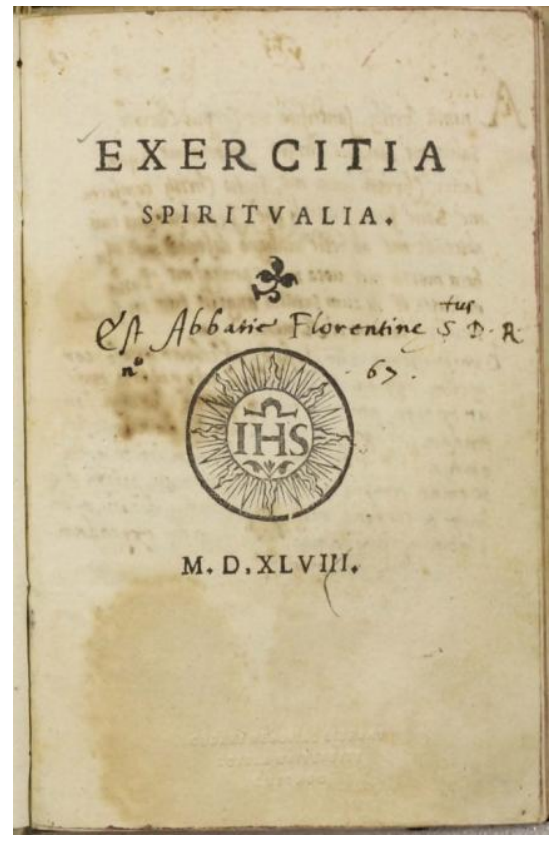

Fig. 1 Versio Vulgata de los Ejercicios publicada en 1548 en Roma por el editor Antonio Bladio. colegio y con ingreso independiente. Aunque siempre van a depender de un colegio.

Si bien en 1569 los benedictinos cedieron a los jesuitas dos amplias casas en Cambrai, Francia; se considera como la primera casa destinada a la práctica de los Ejercicios Espirituales a la Quinta de Val do Rosal ${ }^{2}$, cercana a Lisboa, donde Inácio de Azevedo dirigió varios turnos de 5 y 6 ejercitantes antes de partir para su desafortunado viaje a Brasil en 1570. Aunque también san Francisco de Borja había convertido en cen-

\footnotetext{
${ }^{1}$ O’Neill y Domínguez, 2001: 1223.

${ }^{2}$ Las tierras del "Pico do Cardo", fueron donadas a los jesuitas del Colegio de Santo Antão de Lisboa en dos fracciones, una por D. Margarida Landim de Maia y la otra por Alonso Bothelo. Allí los ignacianos construyeron una casa destinada a los jesuitas enfermos y para retiro espiritual.
} 
tro misional y casa de Ejercicios su retiro en la ermita de la Magdalena (1551-1553) ${ }^{3}$. Pero la verdadera difusión de estos ámbitos evolucionó sistemáticamente en la segunda mitad del siglo XVII y plenamente en el siglo siguiente.

San Ignacio requirió del mencionado duque de Gandía para que intercediera ante el Papa, a los fines que los Ejercicios tuvieran su aprobación y recomendación a partir de su primera publicación. Finalmente la Congregación General de 1608 determinó que todos los jesuitas debían practicar los Ejercicios. Al principio los hacían solo miembros de la Compañía de Jesús, desde los novicios hasta los profesos. Con el tiempo, se incorporaron otros religiosos, monjas, autoridades civiles y finalmente seglares.

\section{Los Ejercicios en la Provincia del Paraguay}

Desde la creación del Noviciado de la provincia, el P. Diego de Torres recordó la asidua práctica de los Ejercicios entre los jóvenes novicios. Pues era una de las seis experiencias que debían realizar antes o durante su probación. El P. Torres al referirse a ellos, manifestó en una Carta Anua: "Los Santos Ejercicios, empero, no se hacen aquí, como en Europa, por un mes entero, sino sólo por algunas semanas, repartidas por el tiempo de la primavera y el invierno" ". Más precisamente: "por ocho o diez días", expresa su sucesor el P. Pedro de Oñate ${ }^{5}$. Incluso y trasladándonos a los tiempos de la expulsión, los alumnos del Convictorio recibían los Ejercicios. Testimonio de ello dejó el P. Miranda, al escribir la biografía del P. Muriel, cuando en tiempos que era rector, escribió: "Lo que más brecha hizo en los ánimos de aquellos jóvenes fueron los Ejercicios de San Ignacio que se dio e hizo con ellos". Efectivamente todos los años el P. Muriel los hacía con los jóvenes, cuatro horas cada uno de los ocho días ${ }^{6}$.

El practicar los Ejercicios era un estímulo singular para los misioneros, así también lo informó el P. Torres cuando transcribió una carta del P. Horacio Vecchi, protomártir que misionó por Arauco y Chiloé. En estas islas estuvo cuatro meses catequizando indígenas con el P. Aranda, y al volver a Arauco encontraron el riguroso invierno de aquellas regiones $\mathrm{y}$ :

"no nos fue posible salir por entonces a doctrinar los indios de aquel estado, que ya estaban poblados en veinte pueblos pareciéndome buena coyuntura para cobrar algunas fuerzas espirituales me determiné hacer los ejercicios juntamente con el P. Aranda",

También en las primeras reducciones de guaraníes, cuenta el P. Torres en 1613 que, ya fundados cuatro pueblos, a cargo del superior José Cataldino, era un aliciente para tanto trabajo la práctica ignaciana, y escribía: "lo que más estimo de los Padres es que con estar dos solos con tantos cuidados a cuestas procuraban ser tan puntuales en

\footnotetext{
${ }^{3}$ La ermita de Oñati Santa María Magdalena se encuentra en Gipuzkoa. No queda prácticamente nada del edificio original. Si bien las primeras noticias vienen de 1442, en una vivienda adjunta vivió durante algunos años el por entonces novicio san Francisco de Borja.

${ }^{4}$ Leonhardt, 1927: 39. Carta Anua firmada por el P. Diego de Torres el 8 de abril de 1614.

${ }^{5}$ Ibíd., 1928: 39. Carta Anua firmada por el provincial Pedro de Oñate en el año 1616.

${ }^{6}$ Miranda, 1916: 217.

${ }^{7}$ Leonhardt, 1927: 61. Carta Anua firmada por el P. Diego de Torres el 6 de junio de 1610.
} 
los ejercicios espirituales y los demás que usa la Compañia”.8. Su sucesor el P. Oñate agrega al referirse al colegio de Asunción que:

"sirve como de refugio para los Padres que andan trabajando en las misiones donde por algún tiempo se recogen a tomar nuevas fuerzas "in vtroq homine" haciendo los Ejercicios Espirituales de la Compañía con lo que se hace más llevadero el trabajo tan excesivo".

Aunque no necesariamente recurrían al colegio, pues el mismo P. Cataldino, ya anciano: "salió de San José para irse a Santo Tomé con el fin de hacer los Ejercicios Espirituales anuales, como se acostumbra" 10 .

Las Cartas Anuas, tanto del P. Torres como de sus sucesores, siguen informando de la periodicidad con que los jesuitas realizan los Ejercicios Espirituales ${ }^{11}$, pues ante tanto trabajo:

"no olvidan de ningún modo los nuestros de cuidar de sí mismos. Suelen juntarse en el fortín de Arauco todos los misioneros esparcidos entre los indios. Después de hacer según costumbre, los Santos Ejercicios, han renovado sus votos, para volver con nuevos bríos al trabajo",

Fue precisamente en Santiago de Chile, donde sus habitantes: "Piden muchos con insistencia los Ejercicios Espirituales, con cese a los que se puede cómodamente y vese en ellos notable reformación de sus costumbres" "13. Aunque dos años antes, el mismo P. Oñate expresa que en Córdoba: "el fruto fue grande, confesándose muchos en casa y comulgando casi todo el pueblo y haciéndose los Ejercicios Espirituales para componer

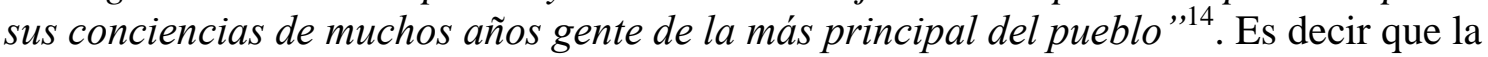
difusión de los Ejercicios Espirituales se fue ampliando y rápidamente llegó a los seglares.

Y si de ellos hemos de referirnos, cabe mencionar el estímulo inapreciable que, como escribe el P. Jarque, tuvo el célebre Antonio Ruiz de Montoya. Precisamente el misionero recibió en Lima su vocación luego de practicar los Ejercicios Espirituales como seglar, previamente a ingresar a la Compañía de Jesús, haciendo por primera vez los Ejercicios en el colegio de San Pablo en $1605^{15}$.

De tal forma que de ministerio propio de los jesuitas, en el siglo XVII pasó a ser una práctica generalizada de la Iglesia, tanto en otras órdenes religiosas como en el clero diocesano. Y también como práctica individual, derivó en retiros masivos. Tanto es

\footnotetext{
${ }^{8}$ Ibíd.: 166. Carta Anua firmada por el P. Diego de Torres en febrero de 1613.

${ }^{9}$ Ibíd., 1928: 75. Carta Anua firmada por el P. Pedro de Oñate en 1617.

${ }^{10}$ Ibíd.: 664. Carta Anua firmada por el P. Diego de Boroa el 13 de agosto de 1637.

${ }^{11}$ Ibíd., 1927: 303, 323 y 421.

${ }^{12}$ Ibíd.: 377. Carta Anua firmada por el P. Diego de Torres el 8 de abril de 1614.

${ }^{13}$ Ibíd.: 159. Carta Anua firmada por el P. Pedro de Oñate el 22 de abril de 1618.

${ }^{14}$ Ibíd, 1928: 67. Carta Anua firmada por el P. Pedro de Oñate en 1616.

15 Jarque, 1900: 143.
} 
así que al suprimirse la Compañía de Jesús la práctica ignaciana continuó y siguió extendiéndose $e^{16}$.

Reconocidos créditos también merecen los directores, destacándose en el territorio los Ejercicios que se hicieron primeramente a individuos en particular. Es el caso del P. Tomás Donvidas ${ }^{17}$, quien fue director espiritual del obispo de Buenos Aires, fray Cristóbal de la Mancha y Velasco (1645-1673) a quien confió la dirección de los Ejercicios cuando aquel era rector del colegio de Buenos Aires, entre 1672 y $1675^{18}$.

También se destacó el otrora rector del Colegio Máximo y provincial, el P. Francisco Vázquez de la Mota, quien dio los Ejercicios hasta su más avanzada edad. Por eso en su obituario se recordó que: "Recomendaba frecuentemente los incomparables Ejercicios de San Ignacio, y los hacía con gran consuelo y provecho espiritual","

Antes de 1700 la práctica de los Ejercicios Espirituales llegó a generalizarse en la provincia del Paraguay, debido a la buena predisposición de algunos jesuitas para este ministerio $^{20}$. Y entre ellos se destacó el P. Miguel Ángel Serra ${ }^{21}$. Su compatriota el P. Machoni menciona su actividad primeramente en Córdoba (1678-1681) y luego en Santa Fe (1681-1691). En la ciudad de Córdoba: "Exhortó a muchos a hacer los Ejercicios Espirituales de Nuestro Santo Padre, con cuyo uso se experimentó gran reforma de costumbres, entablando, por este celestial medio muchas personas una vida quieta, ejemplar y pacífica, con ser antes el tropiezo y escándalo de la ciudad". Pues fue el P. Serra quien introdujo a los seglares en la práctica constante: "en otro tiempo era materia casi imposible persuadir este sagrado retiro a los seculares por no tener conocimiento de su valor y eficacia"22. En Santa Fe alcanzó el rectorado y recordemos que tiempo atrás había rechazado el de Asunción, pero estaba arraigado a la ciudad donde: “daba aquí los Ejercicios de nuestro Padre San Ignacio a los externos con notables mudanzas de sus vidas"23. Tal es así que, luego de la práctica del ministerio, ingresaron varios coadjutores, entre ellos Jorge Soares de Macedo (Obidos, 1634-Santa Fe, 1693), un portugués que había sido enviado en 1677 por el rey Pedro de Portugal para hacer un reconocimiento de las tierras donde fundaron Colonia del Sacramento en 1680. También y por influjo de los Ejercicios del P. Serra, ingresó a la Compañía de Jesús en 1685 el alcalde ordinario de Santa Fe José Domínguez de Sanabria (Santa Fe 1638-Córdoba, 1718). A su vez in-

\footnotetext{
${ }^{16}$ Nótese que además de la madre Antula (beata María Antonia de la Paz y Figueroa), ferviente devota y continuadora de los Ejercicios tras la expulsión, también san José Gabriel Brochero promovió la práctica, construyendo un casa en la Villa que lleva su nombre, que hoy es Monumento Nacional.

${ }^{17}$ El P. Donvidas nació en Arévalo, Ávila el 22 de diciembre de 1618, ingresando a la Provincia de Castilla en 1635. Llegó a Buenos Aires en 1640 y profesó sus últimos votos en Asunción en 1656. Fue provincial en dos períodos 1676-1677 y 1685-1689, procurador en Europa entre 1679-1681 y visitador y provincial de Chile entre 1692 y 1695, cuando fallece en Santiago el 2 de junio (Storni, 1980: 86). Fue misionero entre los indios de Tucumán, luego Maestro de Novicios y rector de los colegios de Buenos Aires, Asunción y Córdoba.

${ }^{18}$ Charlevoix, 1913: 224.

${ }^{19}$ Page, 2004: 210.

${ }^{20}$ Leonhardt, 1926: 218.

${ }^{21}$ El P. Serra nació en Iglesias (Cagliari, Cerdeña), el 7 de enero de 1638, ingresando a la Compañía de Jesús en Cerdeña en 1657. Llegó a Buenos Aires 15 de marzo de 1674 en la expedición del P. Cristóbal Altamirano, profesando sus últimos votos en San Carlos (Corrientes) en 1676 Muere en Santiago de Chile el 21 de enero de 1697 (Storni, 1980: 269. Page, 2007: 44. Machoni, 1732: 252-345).

${ }^{22}$ Machoni, 1732: 286.

${ }^{23}$ Ibíd.: 292.
} 
tentó hacerlo Baltasar de Arellano (Mendoza, 1649-Santiago de Chile, 1726), quien estaba casado y la mujer no se lo permitió. Sin embargo al morir ella, 14 años después, quedó en libertad de acción e ingresó como coadjutor en 1696, buscando al P. Serra que se encontraba en Chile a quien acompañó hasta su muerte ${ }^{24}$.

La Anua escrita por el provincial Cristóbal Gómez en 1675 da cuenta de lo siguiente: "Puedo mencionar por primera vez en las Anuas, que es costumbre en todos los colegios de la Provincia hacer cada año los Ejercicios Espirituales por ocho días completos". Y los hacían: "desde el día de la Ascención hasta el sábado, vísperas de Pentecostés, hay vacaciones de los estudios mayores, para que todos hagan su retiro espiritual, estando prohibida en este tiempo la entrada a los extraños, por estar en oración todos los profesores y sus discípulos". Se quedaban dos profesores: "hombres maduros de edad" a disposición de las confesiones y de dar los Ejercicios en los dos conventos de monjas de Córdoba. Presidían los Ejercicios los novicios para luego hacerse cargo de los quehaceres domésticos, agregando detalles como que:

"Se juntan todos a la señal de la campanilla, aún los ancianos y los Padres graves, a los fines del Padre espiritual, el cual explica los puntos de las meditaciones de los Ejercicios de San Ignacio. Todas estas distribuciones se hacen con tal puntualidad y fervor, que parece que sopla un ambiente celestial,"25.

Las menciones sobre los Ejercicios Espirituales y sus directores son numerosas. En Asunción y después del regreso de los jesuitas a su colegio en 1728, los dirigió su rector el P. Antonio Alonso, comenzando con el obispo fray José de Palos ${ }^{26}$. En Tucumán y Buenos Aires el P. José López; en Córdoba quienes fueran provinciales, los PP. Jaime de Aguilar y Lorenzo Rillo ${ }^{27}$, quien además introdujo los Ejercicios en La Rioja, sucediéndolo el P. Pedro de Arroyo ${ }^{28}$. En Buenos Aires fueron promotores fundamentales los PP. José Pablo Castañeda y Nicolás Ignacio de la Roca. En Salta daba los Ejercicios al clero el P. Gabriel Novat ${ }^{29}$.

\section{Las primeras Casas de Ejercicios}

Los Ejercicios se hacían, como dijimos, en sitios especiales de los Colegios. Pero creemos que la primera Casa de Ejercicios de la provincia fue el edificio que se había construido para Noviciado en 1700, aunque como el general Tamburni desautorizó la obra y los novicios se trasladaron nuevamente al predio del Colegio Máximo en 1714, el mismo general Tamburini lo destinó para los Ejercicios Espirituales:

"es mi voluntad, quede destinada para Casa de Ejercicios, la que lo era de Noviciado en la ciudad de Córdoba, ordenando al mismo tiempo, que ninguno de

\footnotetext{
${ }^{24}$ Ibíd.: 293 y Furlong, 1962: 279.

${ }^{25}$ Page, 2004: 229.

${ }^{26}$ ACS. Carta Anua 1720-1730. f. 23. Estante 6 y 12.

${ }^{27}$ Page, 2004: 283 y 284.

${ }^{28}$ ACS. Carta Anua 1720-1730. F. 23. Estante 6 y 12.

${ }^{29}$ El P. Novat nació en Madrid el 11 de abril de 1691, ingresando a la Compañía de Jesús del Paraguay en 1709, aunque recién llegó a Buenos Aires en 1712 con la expedición del P. Burgés. Sus últimos votos los profesó en Córdoba en 1726 y fue procurador electo en la Congregación de 1738, aunque no viajó a Europa. La expulsión lo sorprendió en el colegio de Asunción, falleciendo en Faenza el 15 de enero de 1770 (Storni, 1980: 200).
} 
los nuestros viva en ella, sino que mientras no estuviere empleada en Ejercicios, la habite y cuide un secular de satisfacción, si fuere necesario „30. 1720:

Su impulsor fue el P. Luis de la Roca ${ }^{31}$, como informa la Carta Anua de 1714-

"La loable costumbre de hacer los Santos Ejercicios por el celo del Padre rector Luis de la Roca, haciéndolo tanto hombres, como mujeres. Así los hicieron este año de 1720 unas 50 mujeres en nuestra iglesia y 25 hombres en nuestra antigua casa de probación. Estaba entre estos últimos el señor obispo y algunos de sus familiares, además de canónicos y otros caballeros distinguidos ${ }^{, 32}$.

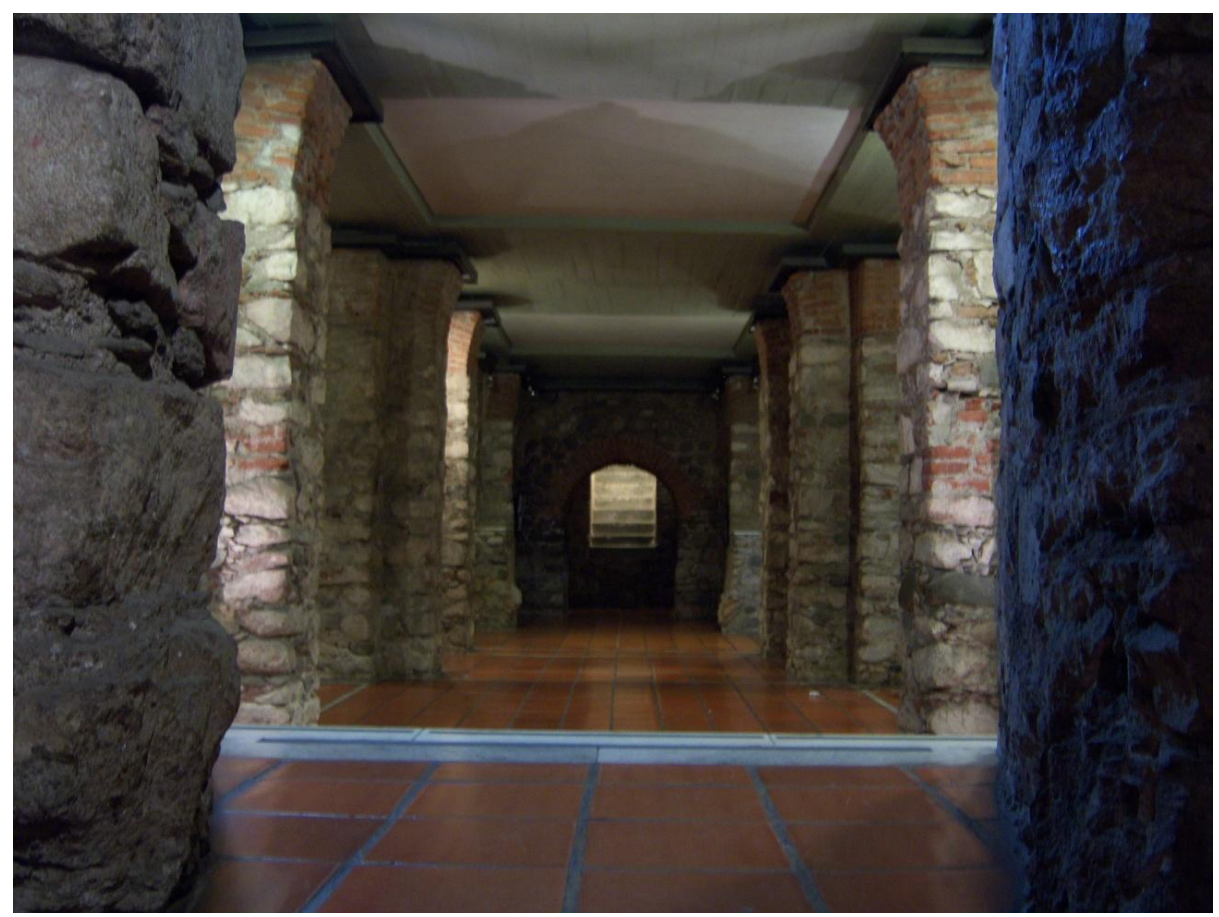

Fig. 2 Restos recuperados de la inconclusa capilla del Noviciado. donde en 1714 pasó a funcionar como Casa de Ejercicios.

El edificio, del que hoy solo queda su cripta subterránea (Fig. 2), era una casa donada por los hermanos Mujica, acondicionada por el H. Jan Kraus y varias descripciones se hicieron de la misma. Por ejemplo en el inventario practicado al tiempo de la expulsión de los jesuitas, realizado por Lorenzo González y el maestro-arquitecto Joaquín Marín, se mencionó que el edificio:

\footnotetext{
${ }^{30}$ Page, 2013: 311.

${ }^{31}$ El P. Roca o Rocafiorita, nació en Catanzano, Italia el 6 de junio de 1658, ingresando a la Provincia de Nápoles en 1675. Llegó a Buenos Aires en 1691 y al año siguiente profesó su cuarto voto en Córdoba. Fue provincial dos años y medio en Chile, donde estuvo desde 1693 a 1712, y dos veces en el Paraguay 1713-1717 y 1722-1726. Entre uno y otro provincialato fue elegido procurador (1721) pero no llegó a embarcarse, falleciendo en Córdoba el 30 de julio de 1734 (Storni, 1980: 242). Fue misionero entre guaraníes y luego profesor de Teología en Córdoba. Después ocupó varios cargos en Chile y regresó a Córdoba.

${ }^{32}$ Page, 2004: 274.
} 
"comprende tres patios, él primero tiene cuatro aposentos, en el paso que va al segundo ay dos, en el segundo patio siete aposentos, comprehendido el refectorio, en el paso del segundo al tercero ay dos aposentos y en el tercer patio hay cuatro, y un lugar común (baño)".

Además detallaron la huerta y su noria, los muebles, cuadros y otros enseres. Finalmente se describió:

"Una iglesia subterránea de tres naves por concluir, con cincuenta pies de largo, y once de ancho, con cuatro arcos de ladrillo, y cal, las columnas de piedra sin labrar, y un panteón ala entrada de veinte pies de largo, y once de ancho todo en bruto que se tasó por el Maestro Arquitecto en 6.550 pesos "33.

Suma que con los otros bienes inventariados del inmueble llegaba a la cifra de $\$$ $15.812,70^{34}$.

En otras ciudades no había disponibilidad de casas, por lo que se continuaron construyeron habitaciones en los Colegios. Efectivamente en Santa Fe, el mismo P. Luis de la Roca en su visita como provincial en 1714, observó que los Ejercicios se daban un par de horas por día y cada uno volvía a su casa. Esto no le agradó y trató de buscar un sitio en el colegio para destinarlo especialmente para los Ejercicios y en su Memorial de 1714 encargó que, además de tiendas de alquiler: "se hagan unos aposentos, q. podrán ser hasta el numero de seis, para entablar entren los Seculares a hazer los Exercicicos de N.S.P." "35. En la Anua de 1730 se mencionan los Ejercicios Espirituales y que: "se han acomodado para este fin varios aposentos de nuestro colegio, apartados de cualquier estorbo". Se destacaba como director el P. Antonio Ligoti ${ }^{36}$.

El P. Furlong lo reafirma al señalar que efectivamente se construyeron detrás de la iglesia, en el patio de parras y naranjos que allí se encontraba, y que fueron ocupados tanto por los ejercitantes como por los indígenas de las misiones que venían a Santa Fe. Entre un mandato y otro del P. Roca, fue provincial el P. José de Aguirre ${ }^{37}$, quien continuó incentivando la práctica en tiempo de Cuaresma. Lo mismo seis años después manifestó el provincial P. Ignacio de Arteaga (1726-1727), agregando que el hombre más capacitado para dar los Ejercicios era el P. José de Astorga ${ }^{38}$.

\footnotetext{
33 Archivo General de la Nación Argentina, (en adelante AGN). Sala IX, 21-9-2, Temporalidades de Córdoba, Legajo 1 (1767-1769).

${ }^{34}$ Barbero: 1998: 40.

${ }^{35}$ AGN, Sala IX, 6-9-5, Memorial del P. Luis de la Roca al colegio de Santa Fe en su visita del 9 de diciembre de 1714

${ }^{36}$ ACS. Carta Anua 1720-1730. F. 38, Estante 6 y 12.

${ }^{37}$ El P. Aguirre nació en Oñate, Guipúzcoa el 31 de julio de 1661, ingresando a la provincia del Paraguay en 1684 y llegando a Buenos Aires al año siguiente en la expedición del P. Diego Francisco Altamirano. En 1691 el obispo Bravo le otorgó el sacerdocio en Córdoba, donde profesó su cuarto voto en 1699. Fue procurador en Europa entre 1714 y 1717 y provincial entre 1719 y 1722, falleciendo en Buenos Aires el 29 de noviembre de 1727 (Storni, 1980: 4).

${ }^{38}$ Furlong: 1962: 283. El P. Astorga nació en Cádiz el 13 de setiembre de 1681, ingresando a la Provincia Jesuítica de Andalucía en 1701. Arribó a Buenos Aires en 1712 con la expedición del P. Francisco Burgés. Sus últimos votos los profesó en Asunción en 1718, falleciendo en la reducción de Apóstoles el 17 de diciembre de 1741 (Storni, 1980: 24).
} 


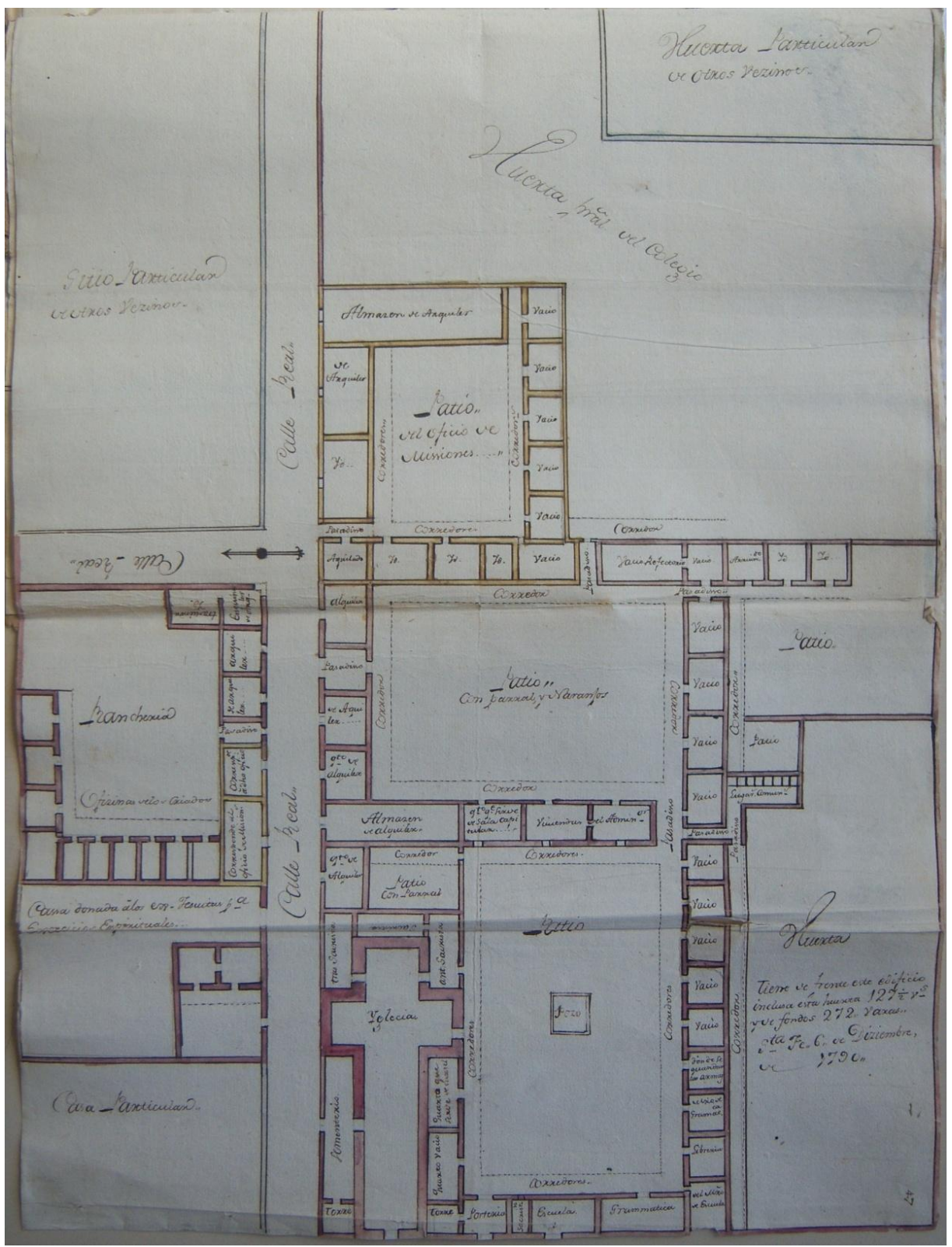

Fig. 3 Relevamiento de las propiedades jesuíticas realizado en 1790. El segundo patio, detrás de la iglesia es el mencionado partió de parras y naranjos. Calle de por medio y colindante a las viviendas de los esclavos, el predio que se destinaría a Casa de Ejercicios de Mujeres (AGN, Sala IX 37-6-5, Leg 148 exp. 39).

También el P. Arteaga bregaba por encontrar un sitio para las mujeres, aunque no se pudo cumplir momentáneamente y debieron hacerlo en forma abierta, es decir acudiendo a un lugar del Colegio y volviendo luego a sus casas. Pero el provincial Bernardo Nusdorffer en 1745 dispuso que se hicieran las diligencias necesarias para "comprar el Corral de $D^{a} M^{a}$ Suarez y a o q á el esta pegado para poder hazer un dia una casa de exercicicos asy para las Señoras "39. Pero no se pudo concretar. No obstante sor María Rosa de Jesús (Da. Rosa de Echagüe y Andía) donó una vieja casa que había comprado en 1764 ubicada junto a las viviendas de los esclavos y que figura en el relevamiento de 1790 (Fig. 3), donde se la denomina "Cassa donada álos ex Jesuitas $p^{a}$

${ }^{39}$ AGN, Sala IX, 6-9-7, Memorial del P. Bernardo Nusdorffer para el colegio de Santa Fe 18 de abril de 1745.

104 Carlos A. Page. Las casas de Ejercicios de los jesuitas en la provincia del Paraguay... 95-120. 
Exercicios Espirituales". En ese plano figuran dos habitaciones chicas y una grande por donde se ingresaba y con patio cercado ${ }^{40}$. La humilde casa de paredes de tierra y techos de tejas fue incluida en el inventario de las Temporalidades y los herederos de la monja reclamaron sus derechos y la vendieron en $1847^{41}$.

En Salta, una de las puertas fundamentales para a evangelización del Chaco, se había abierto un colegio para este fin y se estaba construyendo su iglesia con los fondos donados por el gobernador don Esteban de Urizar y Arespacochaga en 1724. En ese mismo año se comenzó la práctica de los Ejercicios, tanto para hombres como para mujeres, dedicándose a este ministerio el P. Antonio Machoni, rector del colegio, quien consiguió que se reunieran anualmente:

"diversas tandas más de 100 mujeres en unas espaciosas casas, cercanas al colegio, el cual las mantiene gratis durante los Ejercicios. Los hombres se reúnen en el mismo número en nuestra Casa, sin que se estorbe en ella la disciplina regular".

Efectivamente la Casa de Ejercicios estaba ubicada continua al Colegio, siendo construcción "en piedra, de 41 varas en cuadro y con un patio central al que daban las habitaciones" " Los pobladores de Jujuy al ver tan reformados a los de Salta, fueron a buscar al P. Machoni quien se trasladó para allá e improvisó una Casa de Ejercicios en las cercanías de la iglesia de San Roque en: "vasto edificio, el cual, como si fuera convento, pudo contener a gran número de ejercitantes" ${ }^{\text {, } 43}$.

Otras Casas de Ejercicios se fueron levantando a lo largo de la provincia, o en algunos casos como en Corrientes y para la expulsión, el colegio disponía de un terreno para su construcción ${ }^{44}$. El mencionado colegio de La Rioja tenía un segundo patio con carpintería, herrería, cocina, refectorio y una serie de habitaciones que estaban destinadas al alojamiento de los hombres que asistían a los Ejercicios. En la misma ciudad las mujeres contaban con una Casa de Ejercicios que, para la expulsión, se pensó podría servir para el Cabildo, pero la iniciativa no tuvo trámite favorable y concluyó totalmente arruinada ${ }^{45}$. Mientras que en la residencia de San Juan los jesuitas poseían una "hacienda y casa de ejercicios espirituales" donada por el clérigo Pedro Yofré quien pretendió sirva "la mitad de ella para solventar esas prácticas piadosas y la otra mitad para la obra de la edificación de la iglesia. Allí se hallaba la casa con su capilla, refectorio y el equipamiento necesario". La estancia se vendió en 1772 a Francisco Blanco, quien como muchos de los compradores de los bienes jesuíticos nunca terminó de pagar ${ }^{46}$.

La Anua que escribe el P. Lozano para el período 1730-1735, al referirse a los Ejercicios Espirituales expresa:

"Esta práctica está ya aquí muy en boga, y produce efectos admirables en las almas de muchísimos, tanto hombres como mujeres. Hacen ellos los Ejercicios

\footnotetext{
${ }^{40}$ Ibíd., 37-6-5, Leg. 148, exp. 39 Colegio de Santa Fe, 1790.

${ }^{41}$ Calvo, 1993: 36.

${ }^{42}$ Maeder, 2001: 261.

${ }^{43}$ ACS, Carta Anua 1720-1730. F. 42-44v, Estante 6 y 12.

${ }^{44}$ Maeder, 2001:128.

45 ACS, Carta Anua 1720-1730. F. 42-44v, Estante 6 y 12.

${ }^{46}$ Maeder, 2001: 301.
} 
separadamente, a sus determinadas épocas del año y en casas destinadas exclusivamente para este fin ${ }^{, 47}$.

En documento similar, más cercano a la expulsión (1750-1756), se refiere a otros centros urbanos:

"En la ciudad de la Asunción y en Tarija se levantan del mismo modo otros edificios, los cuales, con el fervor de Dios, en breve estarán acabados. Según el ejemplo de estas ciudades, es de esperar que también otras ciudades quieran proporcionarse semejantes asilos ${ }^{, 48}$.

Justamente para la primera, el expulso Francisco Javier Iturri relató que el obispo de Chile, el asunceño Juan González de Melgarejo había dejado la conocida "chacharita del obispo" para sustento de los Ejercicios ${ }^{49}$. Mientras que en una relación anónima de la expulsión del Colegio de Tarija se menciona que allí: "había una casa dispuesta a propósito para ese fin" ${ }^{\text {, }}$.

\section{La Casa de Ejercicios de Santiago del Estero y el sustento de las mismas}

En Santiago del Estero y para la década de 1720, el teniente de gobernador don Alonso de Alfaro hizo una importante donación para componer el edificio del colegio y dotarlo de algunos libros. Al mismo tiempo aumentaba la costumbre de dar los Ejercicios: "ocupándose en su dirección en especial el P. Martín López, consiguiendo con su gran habilidad que pasase toda la ciudad por los Ejercicios", aunque no podía convencer al mandatario, quien llevaba una vida licenciosa. No obstante el P. López fue persuasivo, hasta que el provincial Luis de la Roca lo invitó formalmente a hacer los Ejercicios y al fin accedió. Quedó impresionado desde el primer día y los hizo completos los ocho días, dejando negocios pendientes. Pero más aún, pensó en construir una casa especialmente para los Ejercicios:

"desde su fundamentos, cerca de nuestro colegio otra casa más suntuosa donde por turno todos los hombres y todas las mujeres de aquella ciudad pudieran retirarse a hacer los Ejercicios. Invirtió para esta obra la suma de 24.000 pesos de plata”.

Además de ello "otros 6.000 pesos entregó a la Compañía para la compra de una estancia, cuyas rentas facilitasen los medios a los colegios de la Provincia”. La casa se edificó frente a la iglesia del colegio, y esta actitud entusiasmó a don Pedro de Echazarraga a donar su fortuna para ayudar a adquirir una estancia ${ }^{51}$.

Como todo ministerio, en especial este, debía ser sustentado económicamente pues los ejercitantes debían permanecer al menos por ocho días sin contacto con el resto de la ciudad y ello significaba erogaciones en su mantenimiento cotidiano. Esta cuestión causó la suficiente sensibilidad para que comenzaran a efectivizarse diversas donaciones, no solo en Santiago del Estero sino también en el resto de la provincia, especialmente Buenos Aires y Córdoba.

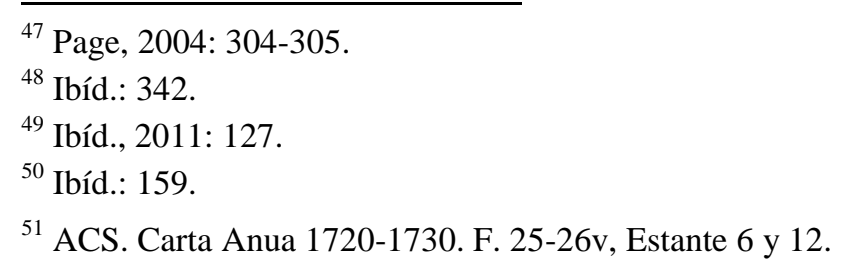


Varias personas hicieron aportes económicos para aquellos que no tuvieran recursos, pudieran practicar los Ejercicios. Así en Córdoba, doña María Suárez dejó por voluntad testamentaria en 1718: "un retazo de solar, que cae junto a las casas del maestre de campo don José de Miranda, para los pobres que hicieran los Ejercicios" "52. Quizás sea esta la primera mención del sustento de los Ejercicios, pero en general los colegios se hacían cargo de esos gastos, facilitando la práctica a personas de escasos recursos e incluso también los esclavos de los jesuitas. Pues la Anua del periodo 17501756 menciona que en la estancia de Santa Catalina se dieron los Ejercicios con 130 personas: "de la clase más baja" nio de Calatayud, escrita desde su exilio en Bolonia, escribe que en Buenos Aires se daban los Ejercicios a españoles, pero también: "a mulatas y negras capaces"

Una de las más gratas noticias al general Tamburini, fue la fundación de la estancia para el sustento de los Ejercicios de la provincia. La hizo el mencionado Francisco de Echazarraga en 1726, sumándose a la donación del gobernador Alfaro. Así lo expresaba en su última carta al Paraguay, fechada el 6 de setiembre de 1727:

"Oygo con indecible consuelo demi corazon el aumento, quetoman los exercicios de N.P.S. Ignacio, viendose entablada en casi todos los Colegios tan fructuosa devocion con grande vtilidad delas almas, y no menor credito dela Comp ${ }^{a}$. Su Antecessor de V.R. el P. Arteaga me avisa dedos quantiosas donaciones, conq la piedad delos Señores D. Alonso de Alfaro, y D. Pedro de Echezarraga (a quien supongo ia en la Comp ${ }^{a}$.) intenta afianzar, y fomentar tan Sto. Ministerio: Y io á este fin ordené en mi Despacho antecedte. varias cosas, cuia puntual observa encargo mucho á V.R. pues juzgo precissar, para su conservacion, y aumento" ${ }^{, 55}$.

Efectivamente el vasco Echazarraga (1685-1762) donó alrededor de 60.000 pesos en efectivo, géneros, depósitos en España, su esclavo Francisco Ignacio, plata y acreencias. Lo hizo: "para comprar y asegurar una finca permanente... que rinda para los gastos que cada Colegio desta Provincia de la Compañía de Jesús del Paraguay hiciere cada año dando los Ejercicios ",56. Pero además de la donación de estos bienes materiales, ingresó a la Compañía de Jesús como coadjutor en $1728^{57}$. Como buen comerciante que era, trabajó muchos años como procurador de la provincia, terminando sus últimos años en Salta.

El encargado de entablar la estancia fue el P. Martín López y el fin de la misma lo confirma el general Retz:

"comprar una Posesion, cuios frutos se expendan en los siguientes fines: en costear los gastos, que cada $\mathrm{Col}^{\circ}$ de essa Prov ${ }^{a}$ hiziere, dando cada año los Exerci-

\footnotetext{
${ }^{52}$ AHC. Esc. 1, prot. Leg. 109.

${ }^{53}$ Page: 2004: 347.

${ }^{54}$ AL. 17/3. Escritos del P. Calatayud.

${ }^{55}$ Page, 2013: 319.

${ }^{56}$ AGN. Sala IX, 6-9-6, Carta de donación perpetua de don Pedro de Echazárraga, 20 de julio de 1726.

${ }^{57}$ El H. Echazarraga nació el 22 de noviembre de 1685 en Villaro, Vizcaya, ingreando a la Provincial Jesuítica del Paraguay el 18 de enero de 1728. Sus primeros votos los profesó dos años después, y sus últimos en 1739. Falleció en Salta el 16 de junio de 1762 (Storni, 1980: 88).
} 
cios á los Seglares, que los quisieren hazer; y paraque los Colegios imbien todos los años Sugetos, que hagan Missiones por sus Partidos ",58.

La construcción del edificio de la estancia fue dirigida por el arquitecto H. Giovanni Andrea Bianchi, cuando se encontraba en Córdoba realizando varias supervisiones (Fig. 4). La obra demandó dos años, incluso su capilla con sacristía, ricamente ornamentada, con un retablo dorado presidido con un cuadro de San Ignacio y la Virgen, flanqueado por una imagen de bulto de San Ignacio a la izquierda y de San José a la derecha. También había una escultura de Santa Rosa, otra de Nuestra Señora de la Concepción y un Cristo Crucificado, además de varios cuadros. Las extensas tierras tuvieron 16 puestos, mientras que el edificio del casco era de piedra y barro con piso enladrillado con cubierta de cañizos y tejas. Lo componían la ranchería, la residencia con un patio de naranjos y limones, con siete habitaciones más el refectorio hacia una amplia galería con once columnas de madera labrada. En un segundo patio había otras cinco habitaciones donde estaba la estañera, sombrerería, cocina y herrería y demás cuartos de servi$\operatorname{cios}^{59}$. Los restos arqueológicos fueron demolidos por sus actuales propietarios.

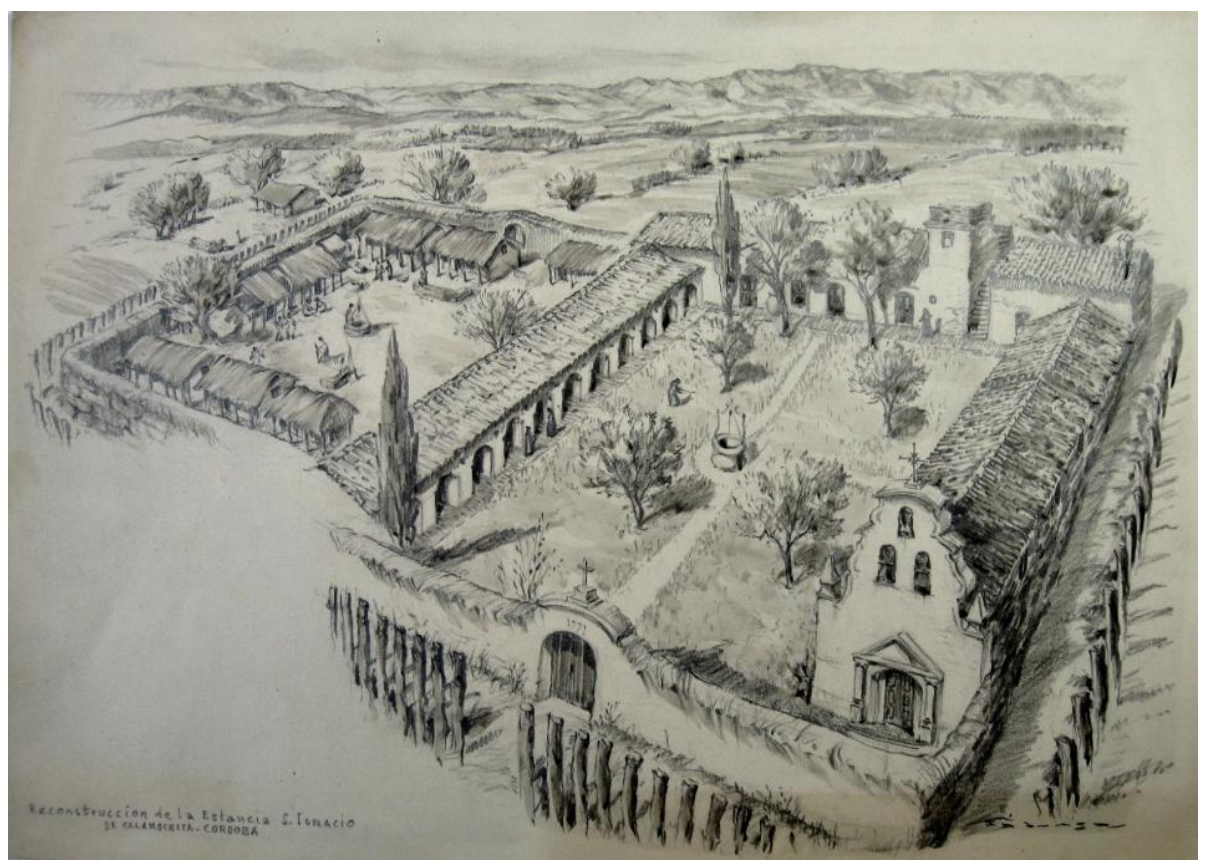

Fig. 4 Interpretación de la estancia de San Ignacio de Calamuchita realizada por el artista Francesc Fábregas y Pujadas en 1957 (Page y Schávelzon, 2012: 270).

Las donaciones en Córdoba continuaron. Así por ejemplo poco antes de la expulsión, el jesuita Manuel Ribeiro (1729-1790), natural de Río de Janeiro, estando para profesar sus últimos votos en Córdoba, donó a favor del colegio de Río de Janeiro sus bienes para que a disposición del general sean vendidos y con ello destinase a la Casa de Ejercicios de esa ciudad ${ }^{60}$. Un año después la mencionada santafesina doña Rosa de Echagüe, al profesar como monja carmelita entregó:

"una casa que tengo cerca del Colegio Máximo de la Compañía de Jesús, como consta por escritura pública que para en poder de mi hermano (político) don

\footnotetext{
${ }^{58}$ Page, 2013: 278.

${ }^{59}$ Page, 1998: 25 y 26.

${ }^{60}$ AHC. Esc. 1, Leg. 147. 19 de diciembre de 1765.
} 
José de Uriarte, la doy a dicho Colegio para el fin de que se sirva para los Ejercicios $^{, 61}$.

\section{Las Casas de Ejercicios de Buenos Aires}

\section{La desaparecida Casa de Ejercicios de Mujeres}

La práctica de los Ejercicios Espirituales entre jesuitas y seglares que hubo en Buenos Aires, se realizaba en la antigua morada de la Plaza de Mayo, aunque no con la asiduidad que adquirieron al trasladarse a su segundo emplazamiento en 1662 y sobre todo desde las primeras décadas del siglo siguiente. Efectivamente la Carta Anua del período de 1720-1730 expresa que: "después de Córdoba no se encuentra en toda la provincia del Paraguay mayor entusiasmo por los Ejercicios de nuestro santo Padre Ignacio, que en este colegio",62.

Para esa época el P. Carlos Gervasoni escribió una carta, fechada el 15 de abril de 1729, donde manifestó sobre Buenos Aires:

"En el Colegio hay establecidas habitaciones para veinte seculares en que pueden hacer los Ejercicios espirituales, que se les dan varias veces al año. Contigua al Colegio hay una casa para las mujeres, que vienen a tejer a la iglesia. Unos y otros viven retirados ocho días, comiendo y durmiendo, los primeros en el Colegio, las segundas en su casa" ${ }^{, 63}$.

Recordando que todos vivían a expensas de la estancia de Calamuchita. escribiendo:

Otra descripción, aunque inédita y mencionada arriba, nos dejó el P. Calatayud,

"Buenos Aires tenía dos colegios: San Ignacio y Belén, este hace poco ha era Residencia, y cada uno tiene una Casa de Ejercicios pegada, de cal y ladrillo, con 20 o 30 aposentos, como un coleguelo, una para hombres, otra para mujeres, y con su capilla con media naranja, como una pequeña, pero muy aseada Iglesia. Se hicieron estando yo allí. Es grande el concurso, y mucho más el fruto. Este punto de Ejercicios está allá mucho más adelantado que en España "64.

Las mujeres de Buenos Aires se ingeniaron para tener su propia Casa de Ejercicios. Efectivamente, en 1722 hicieron los Ejercicios:

"en una casa especial comprada a expensas de la Provincia, juntamente con algunas erogaciones piadosas, a 4.000 pesos, colegio en frente, calle por medio. Alli hay un aposento para cada una de las que hacen Ejercicios, "65.

La Anua siguiente expresa que se encuentran unas mujeres: "de débil constitución" muy devotas, que: "dedican su vida a la perfección cristiana”, además de una vida austera:

\footnotetext{
${ }^{61}$ Ibídem. Leg. 149. 4 de febrero de 1766.

${ }^{62}$ BCS. Carta Anua 1720-1730, f. 33v.

${ }^{63}$ Buschiazzo: 1941: 201 y 202.

${ }^{64}$ AL. 17/3 Escritos del P. Calatayud.

${ }^{65}$ BCS. Carta Anua 1720-1730, f. 33v.
} 
"Se reúnen ellas cada año en tiempo determinado en una capilla vecina al colegio, donde uno de nuestros Padres les da los Ejercicios de San Ignacio. Hay junto a esta capilla una Casa de Ejercicios, administrada por dos señoras del número de las llamadas Beatas, que se obligan con el voto de castidad a imitar a las monjas clausurales".

Las dos maestras contaban con una buena cantidad de "instrumentos de penitencia", a fin de practicar las devociones. De allí que tenían una Virgen de los Dolores con su típico corazón atravesado de siete espadas ${ }^{66}$.

Efectivamente las mujeres recolectaron fondos para comprar "aquella casa, de por si muy espaciosa”, ubicada en la esquina nordeste de las actuales calles Perú y Alsina, pero por indicación de los jesuitas:

"subdividiéndola en tantas celdas, que cada una de las ejercitantes tiene su propio aposento. Añadióse una capilla, cuyas paredes están adornadas con pinturas, que representan diferentes escenas de la Sagrada Pasión de Jesucristo y que son obra de un pintor romano. Además regalaron varias señoras, cortinas de seda, para aumentar la elegancia del santuario”.

Así mismo: "Tienen su comedor común, escuchando ellas la lectura mientras comen a mediodía y a la tarde ${ }^{, 67}$.

La casa, afirma Levinton ${ }^{68}$, la había construido don Carlos Valente, quien al haber quedado en deuda con los guaraníes misioneros por más de cinco mil pesos, por la construcción de la misma, la entregó para ser usada como Casa de Ejercicios de mujeres.

Para mediados de 1745 aún continuaban las obras de remodelación, según el memorial que dejó el provincial en su visita, quien expresó: “6. Emplee se la plata q dieron para ello, en solo la casa de exercicios. Y formese esta obra con empeño, por la suma falta q haze. Y para mover áun á otros para ajudar á perfeccionarla",69. También aquí hubo sendos donantes como el capitán don José de Villanueva Pico, quien en el verano de 1752 entregó ocho mil pesos para acabar con la Casa a quien sugería como patrona a la Virgen del Buen Consejo, cuya imagen había donado al colegio, recuperada de los ingleses, y quería que fuera colocada en la capilla mayor de la Casa de Ejercicios de mujeres. Ponía por condición que la casa quedara a su cuidado y administración, y en su ausencia dejaría esa potestad al rector del colegio. A los cuatro días, la donación fue aceptada por el entonces vice rector P. Juan José Montenegro, pero con la condición que si no alcanzaba ese dinero, el donante debía poner el resto ${ }^{70}$. Finalmente Villanueva dejó en el testamento, firmado en agosto de ese mismo año, que dejaría 1.200 pesos más, en caso de haberse gastado la donación inicial ${ }^{71}$.

\footnotetext{
${ }^{66}$ Ibíd. 1730-1735, f. 13v.

${ }^{67}$ Ibídem.

${ }^{68}$ Levinton, 2012: 97.

${ }^{69}$ AGN, Sala IX, 6-9-7. Memorial del P. provincial Bernardo Nusdorffer para el rector del colegio de Buenos Aires y sus consultores en la visita del 3 de junio de 1745.

${ }^{70}$ Ibíd. Sala IX, 6-10-1. Donación de José de Villanueva de ocho mil pesos para la Casa de Ejercicios de mujeres, 20 de enero de 1752.

${ }^{71}$ Ibíd. Declaración de José de Villanueva de cláusula testamentaria, 29 de Agosto de 1752.
} 
Encontramos una la lista de trabajadores, cuyo capataz era un tal Ventura, que trabajó 144 días y ganó 180 pesos. Entre los trabajadores, oficiales y peones, que pasaron por la obra suman 55, había algunos portugueses, un esclavo llamado Cayetano propiedad de don Francisco Sorante, mientras el resto solo son identificados por sus nombres. Se gastaron en ese periodo $\$ 3.028$ de mano de obra y en algunos materiales y herramientas $\$ 3.231^{72}$. En otro documento se inscriben los materiales empleados, principalmente tejas y adobes ${ }^{73}$.

La obra, que incluía una capilla con cúpula, posiblemente que se concluyó en 1754, al menos hasta esa fecha se registran los trabajadores y gastos de la misma ${ }^{74}$.

Sin haber alcanzado los 1.200 pesos que dio de más el bienhechor don Villanueva, también aportó el mencionado Valente: "que fueron mas de veinte seis mil pesos", como le recordó el P. Montenegro al mismo Villanueva que había viajado a España a arreglar un pleito en el que estaba involucrado ${ }^{75}$. Los bienhechores recibieron de los sacerdotes seis misas y de los coadjutores seis coronas por orden del P. visitador Nicolás Contucci ${ }^{76}$.

El P. Furlong reproduce el texto del inventario de la expulsión que expresa de este inmueble: "Tiene cuarenta y seis y media varas de terreno de frente al sur, calle por medio con el Colegio, y formando esquina con la otra frente al Oeste, de veinte y ocho varas y media, que es su fondo". Agregando el historiador jesuita que el mismo informe la describe de la siguiente manera:

"edificio de dos cuerpos, todo de cal y ladrillo y bóveda. Tiene en el cuerpo bajo siete aposentos, una pieza que sirve de refectorio con sus mesas y bancos de firme, tornos de comunicación a la cocina, ésta y otro cuarto que servía de despensa, sus lugares comunes, una pieza que sirve de capilla con otro cuarto para sacristía y seis confesionarios embutidos en las paredes, sus escaleras para el uso del segundo cuerpo, en el que hay diez aposentos, todo con sus puertas y ventanas corrientes, y con corredores altos y bajos, que forman el patio; un pozo; y en la capilla su media naranja con cuatro ventanas en la cúpula",77.

De tal forma el arquitecto De Paula reconstruye su ubicación (Fig. 5), poniendo énfasis en la cúpula y ubicación de esta capilla. En el inventario señalado por el P. Furlong también se mencionan los bienes muebles y ornamentos, donde se destacan siete lienzos con imágenes de santos y otro ubicado en el retablo con la figura de Jesucristo ubicados en la capilla. Tenían además una caja con varios libros y en el comedor cinco mesas con sus asientos, dos docenas de cubiertos, dos docenas de tazas y platos. En las habitaciones se encontraban 24 camas de palo blanco y 21 sillas, entre otras cosas.

\footnotetext{
${ }^{72}$ Ibíd. Razón de los oficiales y peones que han trabajado en la obra de la Casa de Ejercicios y de la plata que se les ha dado desde el dia 11 de junio en cuyo día salió para las misiones el Padre Rector Alonso Fernández hasta el 31 de diciembre de 1753.

${ }^{73}$ Ibíd. Razón el material y teja que se ha comprado para la Casa de Ejercicios desde junio de 1754 hasta junio de 1754 (sic)

${ }^{74}$ Ibíd. Oficiales y peones que han trabajado en la obra desde el mes de mayo de 1754 hasta el mes de octubre de 1754.

${ }^{75}$ Ibíd, Sala IX, 6-10-5. Carta del P. Juan de Montenegro a don José de Villanueva, Córdoba, 23 de junio de 1761 .

${ }^{76}$ Ibíd. Carta del P. Domingo Navarro al visitador Nicolás Contucci, 11 de diciembre de 1761.

${ }^{77}$ Furlong, 1944: 235.
} 


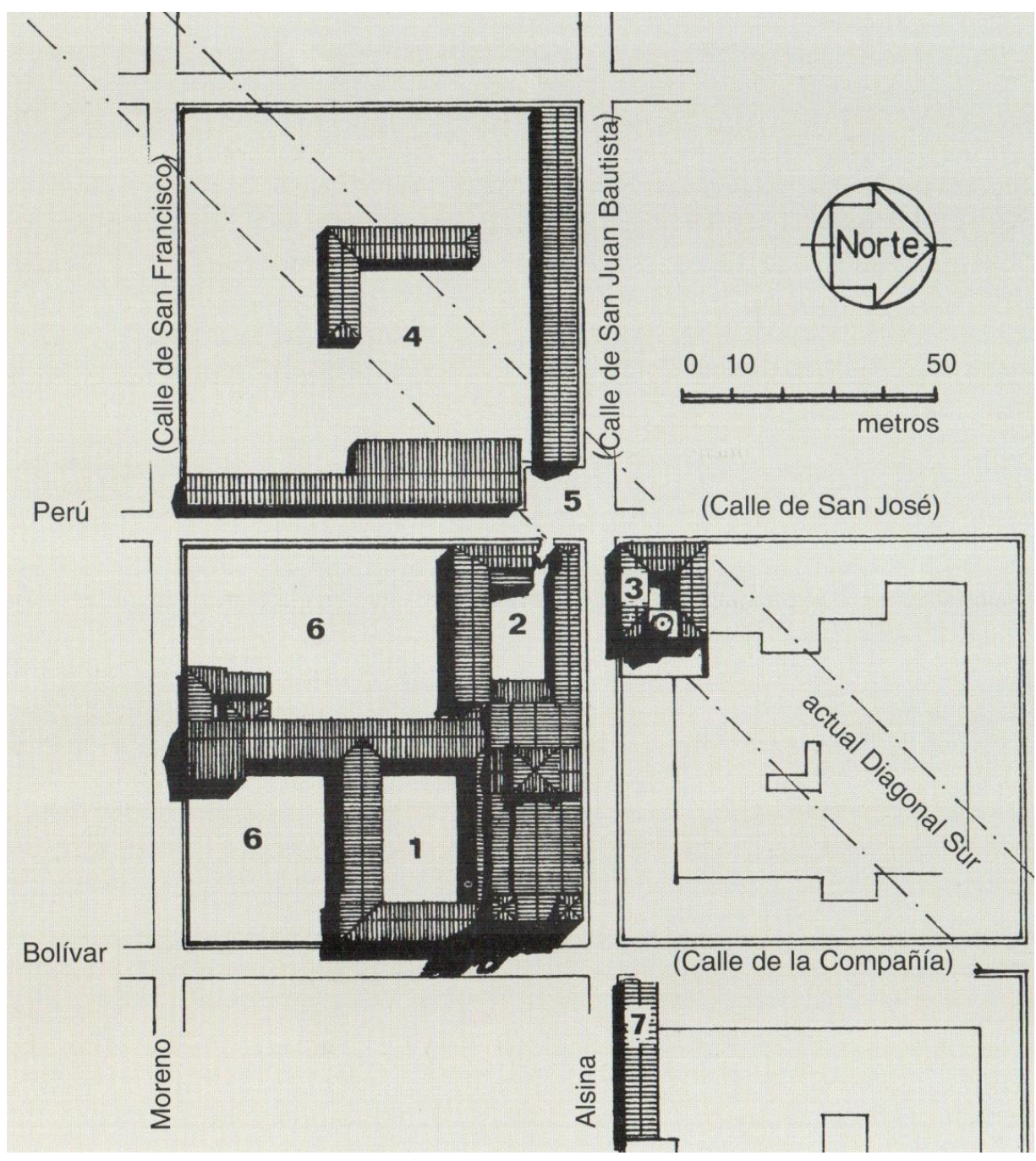

Fig. 5 El complejo jesuítico en Buenos Aires. Con el número 3 la ubicación de la desaparecida Casa de Ejercicios Espirituales para mujeres (De Paula, 1997: 63).

El destino de la Casa de Ejercicios para mujeres fue conflictivo, pues se comenzó con su clausura, hasta que en 1779 el virrey Vértiz ubicó allí la Casa de Niños Expósitos, que funcionó por casi dos décadas hasta que le deparó un nuevo destino, el de cárcel militar. La propiedad fue vendida en 1822 y por casi tres años funcionó la Sociedad Filarmónica. Posteriormente la capilla fue nuevamente consagrada al culto, esta vez de la comunidad anglicana ${ }^{78}$, hasta que se demolió para que circulara la actual Diagonal Sur, proyectada en 1907 y concluida en 1943.

\section{La Casa de Ejercicios para hombres en el Colegio de Belén}

Para 1735, los hombres recibían los Ejercicios: "en el mismo recinto del colegio, cuyas nuevas construcciones, juntamente con la fábrica de la magnífica iglesia, se puede decir, que se levantaron debido a la práctica de los Ejercicios",79.

\footnotetext{
${ }^{78}$ De Paula, 1997: 66.

${ }^{79}$ BCS, Cartas Anuas 1730-1735, f. 13v
} 
Efectivamente en Buenos Aires, se levantó otro colegio donde hacia 1740 se edificaría adjunto, un edificio para Casa de Ejercicios. El colegio al que nos referimos es el que llevó el patrocinio de Nuestra Señora de Belén, ubicado en el ejido de la ciudad en los Altos de San Pedro (hoy barrio de San Telmo), donde el Cabildo comenzó a vender tierras a principios del Siglo XVIII, otorgándoles a los jesuitas una merced de dos manzanas para su emplazamiento ${ }^{80}$. El sitio se consideró al principio como un "apéndice del colegio", pero llegó a componerse de un Colegio con su iglesia y Casa de Ejercicios con su capilla. El proyecto del nuevo colegio se encomendó al H. Giovanni Andrea Bianchi ${ }^{81}$, quien no participó de la construcción pues tuvo que viajar a Córdoba para dirigir los corredores altos del Colegio Máximo ${ }^{82}$. Para esta tarea se trajo de la reducción de San Miguel al H. Prímoli, quien permaneció hasta 1736, siendo sucedido, aunque en forma interrumpida, por el H. José Schmidt hasta 1744, en que fue ayudado por el arquitecto laico italiano Antonio Masella. Las obras fueron lentas y con variadas complicaciones burocráticas que, llegados a la expulsión, aún no se habían concluido.

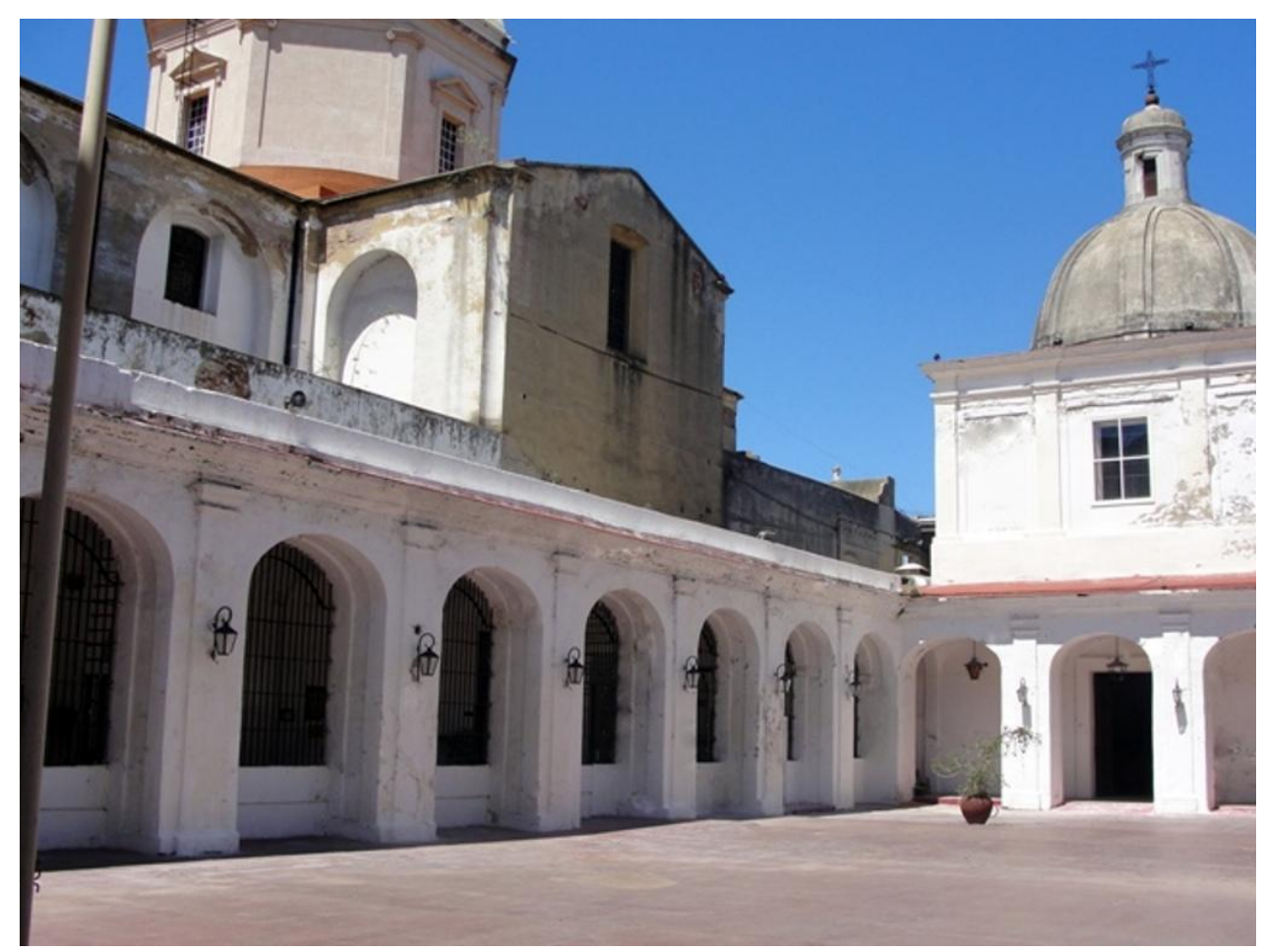

Fig. 6 Fotografía actual que muestra claustros y la capilla de la Casa de Ejercicios para hombres del Colegio de Belén. Hoy Museo penitenciario “Antonio Ballvé”.

La Casa de Ejercicios para hombres se comenzó a construir con el H. Schmidt en vida, hacia 1740, junto al Colegio de Belén (Fig. 6 y 7). Por cierto que para ese año estaba en construcción, pues el provincial P. Machoni ordenaba: "la fábrica de la Casa de Ejercicios se llevará adelante con la plata que se dio y se dará en adelante para ese

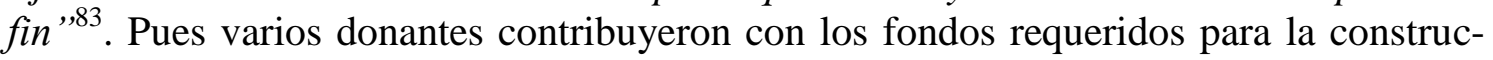
ción de la Casa de Ejercicios para hombres, cuyo costo alcanzó a 170.000 pesos, según

\footnotetext{
${ }^{80}$ Maeder, 2001: 64.

${ }^{81}$ De Paula y Tait, 1960: 84 y Sobrón, 1997: 207.

${ }^{82}$ Page, 2004: 331.

${ }^{83}$ Furlong, 1944: 233.
} 
informó inmediatamente después de la expulsión al conde de Aranda, el obispo Manuel Antonio de la Torre, agregando que "por su construcción no puede servir para otro fin, por estar cada aposento con su bóveda particular, y ser solo capaz de un sujeto" ${ }^{84}$. Así también don Gregorio Otaola aportaba 4.000 pesos, ofreciendo completar su donación con otros 6.000, mientras Melchor García de Tagle había aportado 50.000 pesos y como escribe el P. Villagarcía estaba:

"deseoso de cooperar a su propagación, está labrando a su costa contigua a dicho nuevo colegio una casa bien capaz, en que a cualquier tiempo del año pueden recogerse los que tuvieran devoción, o se sintieran movidos de Dios a hacer dichos Ejercicios, estableciendo también finca segura",85.

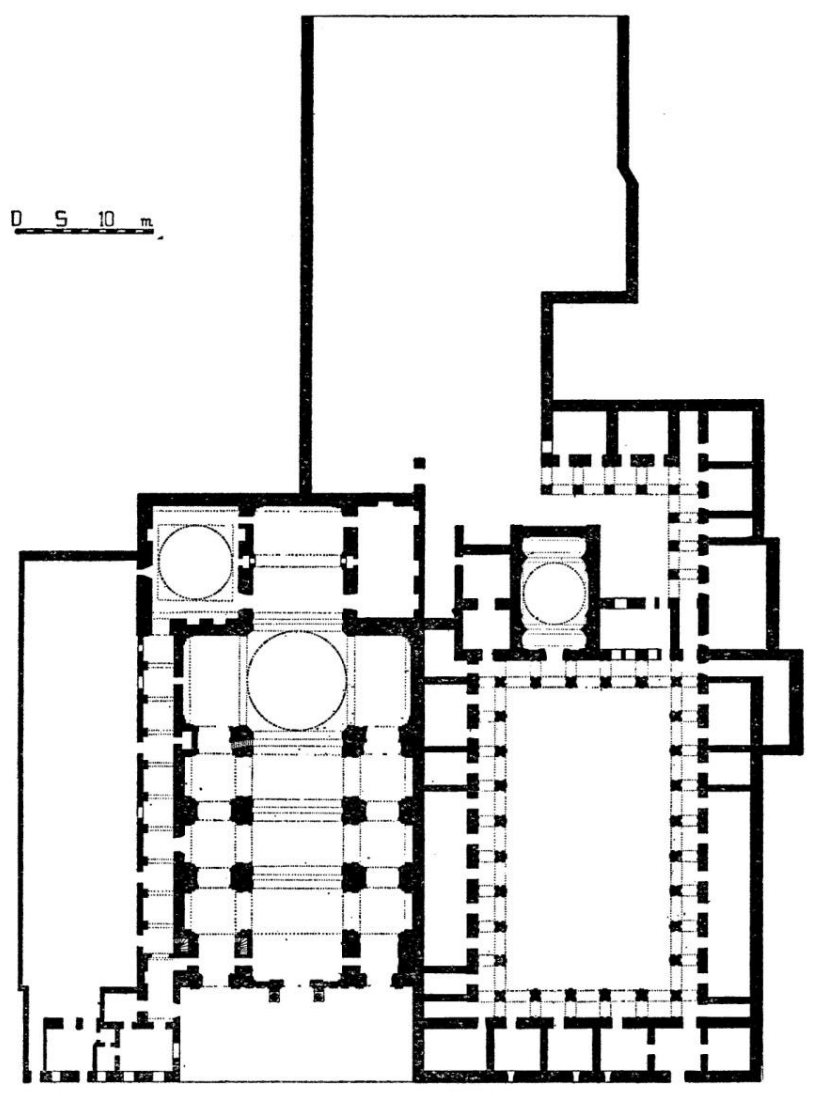

[NLLE DE BELÉN

Fig. 7 Planta de la Iglesia de Belén y a la derecha Casa de Ejercicios con su capilla (De Paula y Tait, 1960: 65).

Hace algunos años los arquitectos De Paula y Tait se ocuparon del estudio de la pequeña capilla de la Casa de Ejercicios y generalizan en Bianchi como autor de los "planos originales", que por otro lado no se han conservado (Fig. 8 y 9). Pero el documento que trae el P. Sobrón limita los ámbitos proyectados. Lo que dicen de cierto De Paula y Tait es que, si bien no han podido establecer la autoría de la capilla, los rasgos indican que tuvo más de un arquitecto interviniente y que fue jesuita, dando a entender

\footnotetext{
${ }^{84}$ Bravo, 1872: 246.

${ }^{85}$ Revista de Buenos Aires. Junio 1865. VII: 231.
} 
que pudo haber sido Schmidt, que por otra parte estuvo en la obra 14 años y murió cuatro después de la donación de García Tagle. Pero es innegable la similitud de la pequeña cúpula con la de la Catedral de Masella, y la linterna con la del convento de Santo Domingo, que proyectó el maestro-arquitecto Manuel Álvarez de Rocha y que coincidentemente en la misma época concluyó la cúpula de la iglesia de Belén ${ }^{86}$.

La Casa de Ejercicios fue el último ámbito que cobijó a los jesuitas expulsos de Buenos Aires y los que venían del interior y debían embarcarse rumbo al exilio ${ }^{87}$. Los primeros en llegar fueron los 42 del Colegio Grande que se sumaron a los 8 del de Belén, desde el 3 de julio hasta mediados de setiembre en que llegaron los PP. de Corrientes, Montevideo, Córdoba y Santa Fe. Los de Buenos Aires embarcaron en la fragata de registro San Esteban.
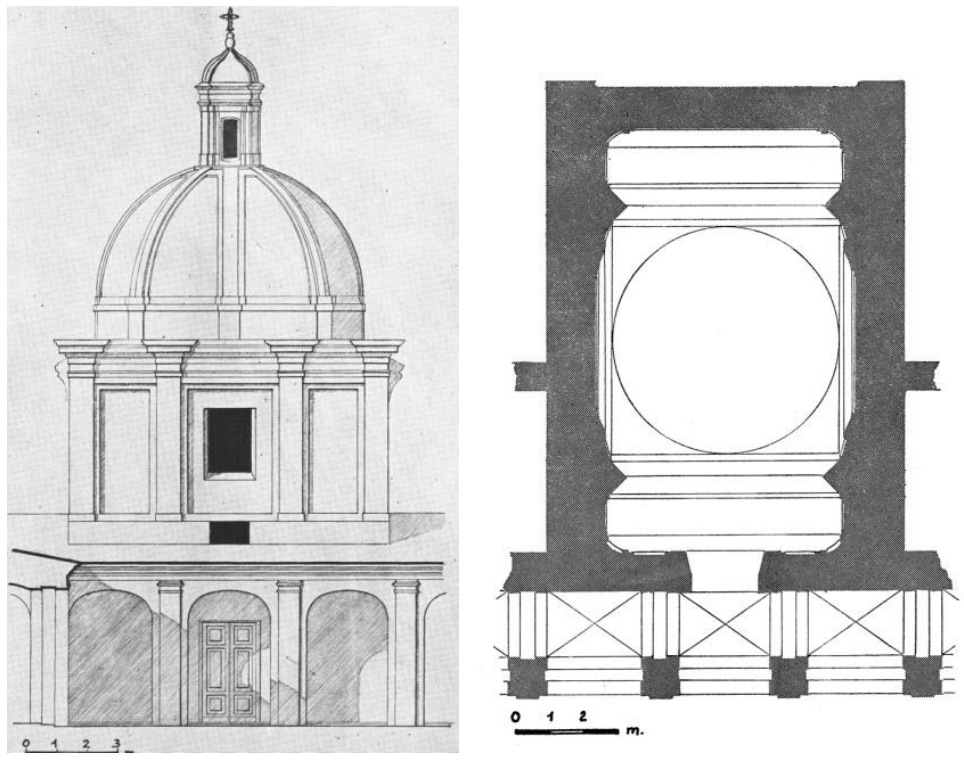

Fig. 8 y 9 Detalles de la fachada y planta de la capilla de la Casa Ejercicios del Colegio de Belén (De Paula y Tait, 1960: 66).

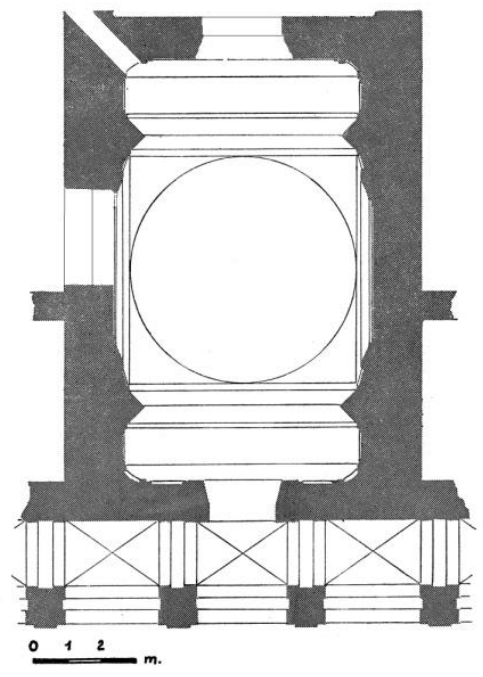

Fig. 10 Relevamiento de la planta según las investigaciones de Schávelzon en 1991 (2012: 21).

Para la expulsión, los inventarios que se realizaron describieron la Casa: "es todo de cal y ladrillo y bóvedas sin altos con capilla, ventidos aposentos, corredores, refectorio y demás oficinas necesarias ${ }^{\prime 88}$. Los betlemitas la reclamaron para instalar un hospital, argumentando que en la donación de García Tagle decía que si la Casa los jesuitas la abandonaban debía pasar a los betlemitas. Pero la Junta de Temporalidades no se las concedió y en 1773, durante la gobernación de Vértiz, decidieron asignarla para “casa de corrección de mujeres de mal vivir", confirmada por Real Cédula de 1779. Igualmente los ornamentos e imágenes fueron entregadas en 1786 a la madre beata María Antonia de San José, aunque devolvió el cuadro de Nuestra Señora de Belén "por ser

\footnotetext{
${ }^{86}$ De Paula y Tait, 1960: 89.

${ }^{87}$ En ese momento se hallaban en el colegio de Belén cuatro sacerdotes y tres coadjutores. Eran ellos, el Padre rector Juan Bautista Roca y los sacerdotes José Quiroga, Ignacio Oyarzabal y Joaquín Montaner junto a los coadjutores Rafael Saura, Juan Blanco y Jacobo Baur. Mientras que en las estancias del colegio se hallaban el Hermano Jorge Arit en la Estanzuela y los Hermanos Agustín Rodríguez y Agustín Aponte en la estancia de Las Vacas. El rector escribió una elocuente relación de lo sucedido en tiempos de la expulsión (Page, 2011: 625-632).
}

${ }^{88}$ AGN. Sala IX, 10-6-3 cit Levinton, 2012: 188. 
grande", y llevó el rostro y manos de la Dolorosa. Con los años fue tomando más fuerza el carácter de cárcel de mujeres bajo la dirección de las Hermanas del Buen Pastor que se mantuvo hasta 1978. En medio de este extenso periodo, al edificio se le agregó un piso en un sector y se modificó su fachada hacia fines del siglo XIX $^{89}$.

A manera de post scriptum, agregamos alguna información sobre este monumento recogida de un trabajo visto mientras éste, esperaba su evaluación. Nos referimos a los aportes arqueológicos realizados por el equipo de Schávelzon en 1991, publicados en ese año y en $2012^{90}$. Definitivamente y con los planos a la vista confirman que la planta alta fue un proyecto de Pedro Benoit de 1883-1884, quien también modificó la fachada de calle Humberto Primo, dándole el lenguaje historicista de moda. Continúa Schávelzon señalando los planos que encontró del edificio, desde el de 1740 de Buenos Aires, el de 1865 con la apertura de la calle Balcarce y luego el señalado de Benoit. Observa y demuestra con las excavaciones, que el nivel interior del edificio fue subido 71 $\mathrm{cm}$, desapareciendo los basamentos y por consiguiente las proporciones del mismo. Encuentra los pisos de ladrillos de las galerías y ninguno en el patio, pues era tradición que hubiera simplemente tierra y quizás frutales. En su centro descubrió el aljibe y los restos de un brocal de mampostería que considera posiblemente el más antiguo de la ciudad. También excavaron en la capilla, encontrando el nivel original del piso $40 \mathrm{~cm}$ más abajo y los cimientos de cuatro metros de profundidad. Debajo del piso original hallaron despojos de lo que podría haber sido una herrería de la misma obra, e incluso restos óseos de tres niños de entre 7 y 12 años y un nonato, desconociéndose quiénes y porqué estaban allí, aunque presentaban rasgos de extrema desnutrición. Además descubrieron una puerta que daba a un "conducto" (muro) cegado que lleva a la pequeña sacristía y otra a la iglesia. También, buscando evidencias de un retablo, descubrieron en el muro posterior, una puerta de arco de medio punto cegada (Fig. 10). Incluso encontraron el color original rojo o "sangre de toro".

\section{Conclusión}

Los Ejercicios de San Ignacio llegaron a la región en coincidencia con la obligatoriedad de practicar los mismos, declarada en la Congregación General de 1608. De tal forma que desde los novicios a los profesos comenzaron el ministerio, extendido al resto del clero y luego a los seglares. Estos últimos al principio no se retiraban, sino que hacían los Ejercicios un par de horas en los colegios y luego volvían a sus casas.

Varios jesuitas se destacaron en cada rincón de la provincia como directores espirituales, existiendo una documentación muy rica sobre los mismos. Aunque la mayoría proviene de los jesuitas, pero obispos como el doctor Juan de Sarricolea y Olea en un informe que elevó al Papa Clemente VII en 1730, destaca entre otras virtudes de los jesuitas la:

"admirabilísima ejercitación de los ejercicios espirituales del padre fundador San Ignacio, a la cual, anualmente, tanto a hombres como a mujeres de cualquier clase, estado y condición, incluso ínfima y servil, en determinado orden

\footnotetext{
${ }^{89}$ Actualmente el antiguo conjunto jesuítico es sede de la Academia Superior de Estudios Penitenciarios y del Museo Penitenciario Argentino "Antonio Ballvé". Monumento Nacional 1982-05-26 Decreto 1034.

${ }^{90}$ Schávelzon, 2012.
}

116 Carlos A. Page. Las casas de Ejercicios de los jesuitas en la provincia del Paraguay... 95-120. 
sucesivo, en lugares oportunos destinados a ello, convocan, exhortan e invitan por las plazas, por las vías públicas, por cada casa, caminando de puerta en puerta, como mendigando almas, lo único que buscan para si, a fin de lograr ganancias para Cristo"

Los primeros ámbitos destinados a este ministerio fueron algunas habitaciones de los colegios o bien construidas especialmente como las seis que ordenó levantar el provincial Luis de la Roca en Santa Fe en 1714. También en un segundo patio retirado poseía seis habitaciones el colegio de La Rioja, y en Buenos Aires los jesuitas habían destinado al principio habitaciones para veinte seculares. Pero como para los Ejercicios debía haber separación de sexos, las mujeres fueron las primeras en poseer sus propias casas, ya que no era bien visto que los hicieran dentro de los claustros de los colegios. Así pasó en Santa Fe, La Rioja, Tarija, Santiago del Estero y demás ciudades.

De tal modo que aparecen casas acondicionadas para los Ejercicios o bien levantadas para ese fin. En el primer caso, el edificio preparado para el Noviciado sirvió para Casa de Ejercicios desde 1714, al disponerle ese nuevo destino el propio general Tamburini. Mientras en otras ciudades se levantaron especialmente, como en Santiago del Estero con donación expresa del gobernador Alonso de Alfaro y Buenos Aires que tuvo una para mujeres y otra para hombres, siendo esta última la única que subsistió hasta la actualidad. Incluso en la primera se daban ejercicios a las esclavas.

El sustento de la práctica, donde se demandaba alimentar y mantener por ocho días a los ejercitantes, también consiguió donaciones importantes como haciendas, tanto la del obispo Melgarejo en Asunción, como principalmente la de San Ignacio de Calamuchita en Córdoba del comerciante Pedro Echazarraga que solventaría los gastos de todas las Casas de la provincia.

De manera general las Casas se ordenaban con un patio central con galerías donde se abrían habitaciones. Pues si bien es una distribución claustral tradicional, tenía la particularidad que las habitaciones eran pequeñas, para una sola persona. A ellas se sumaban una capilla, refectorio-cocina y lugares comunes (baños) que eran para uso comunitario de los ejercitantes.

Después de la expulsión y con la administración de las Temporalidades, las Casas de Ejercicios en su mayoría quedaron sin funciones específicas y luego fueron vendidas, como la de Salta a Nicolás Severo de Isasmendi en $1786^{92}$. Excepto la de hombres en Buenos Aires que se destinó para Casa de Corrección y la de mujeres para alojamiento de los Niños Expósitos. En Córdoba la Casa de Ejercicios se entregó a los Betlemitas para instalar un hospital provisorio, mientras que el edificio del Noviciado, ubicado en la manzana del Colegio, se destinó para Casa de Ejercicios en 1797.

Así es como los Ejercicios Espirituales continuaron realizándose, sobre todo por la persistencia de María Antonia de la Paz (1730-1799) que no solo siguió la práctica sino que también promovió la construcción de nuevos edificios que llevaron las mismas características funcionales.

\footnotetext{
${ }^{91}$ Barbero, 1995: 134.

92 Maeder, 2001: 272.
} 


\section{Fuentes documentales}

ACS. Archivo Colegio del Salvador de Buenos Aires.

AGN. Archivo General de la Nación Argentina.

AHC. Archivo Histórico de la Provincia de Córdoba Argentina.

AL. Archivo de Loyola en Azpeitia.

\section{Bibliografía}

Barbero, Estela Rosa (1998). Compañía de Jesús y Temporalidades de Córdoba. Buenos Aires: Archivo General de la Nación.

Barbero, Santiago; Astrada Estela M. y Consigli, Julieta (1995). Relaciones ad Limina de los Obispos de la Diócesis del Tucumán (s. XVII al XIX). Córdoba: Prosopis Editora.

Bravo, Francisco Javier (1872). Colección de documentos relativos a laq expulsión de los jesuitas de la República Argentina y del Paraguay... Madrid: Est. Gráfico de José María Pérez.

Buschiazzo, Mario J. (1939). "Iglesia de Nuestra Señora de Belén de la parroquia de San Pedro Telmo", Boletín de la Comisión Nacional de Museos, Monumentos y Lugares Históricos. Buenos Aires, Vol. 1, pp. 151-155.

- (1941). Buenos Aires y Córdoba en 1729. Según cartas de los padres C. Cattaneo y C. Gervasoni SJ. Buenos Aires: Compañía de Editoriales y Publicaciones Asociadas.

Calvo, Luis María (1993). La Compañía de Jesús en Santa Fe. La ocupación del espacio urbano y rural durante el dominio hispánico. Santa Fe: Ediciones Culturales Santafesinas.

Charlevoix SI, Pedro Francisco Javier (1913). Historia del Paraguay. Madrid: Librería General de Victorino Suárez. T. 3.

De Paula, Alberto S. J. (1997). Manzana de las Luces. Colegio de San Ignacio. Buenos Aires: Manrique Zago ed.

De Paula, Alberto S. J. y Tait, Teófilo Victor (1960). "La Capilla de Ejercicios Espirituales del Colegio de Belén, en Buenos Aires". Anales del Instituto de Arte Americano e Investigaciones Estéticas. $\mathrm{N}^{\mathrm{o}} 13$.

Furlong SJ, Guillermo (1944). Historia del Colegio del Salvador y de sus irradiaciones culturales y espirituales en la ciudad de Buenos Aires. 1617-1841. Buenos Aires. T. I.

- (1962). Historia del Colegio de la Inmaculada de la ciudad de Santa Fe y sus irradiaciones culturales, espirituales y sociales. 1610-1962. Buenos Aires: Ex alumnos del Colegio. T. I.

García Jiménez de Cisneros (1965). Obras Completas II. Exercitatorio de la vida spiritual. Abadía de Monserrat, 1965. 
http://descargas.cervantesvirtual.com/servlet/SirveObras/0692628426684826213 2268/015094.pdf?incr=1

Jarque, Francisco (1900). Ruiz de Montoya en Indias (1608-1652). Madrid: Vitoriano Suárez ed.

Leonhardt SJ, Carlos (1962). "Ensayo Histórico sobre las Casas de Ejercicios en la Argentina y apostolado de la venerable madre sor María Antonia de la Paz", Estudios de la Academia del Plata, $\mathrm{N}^{\mathrm{o}} 183$.

(1927). Documentos para la Historia Argentina. Iglesia. Cartas Anuas de la Provincia del Paraguay, Chile y Tucumán de la Compañía de Jesús. T. XIX.

(1928). Documentos para la Historia Argentina. Iglesia. Cartas Anuas de la Provincia del Paraguay, Chile y Tucumán de la Compañía de Jesús. T. XX.

Levinton, Norberto (2012). Arquitectura de la Compañía de Jesús en Buenos Aires. La creación y el paso inclemente del tiempo. Buenos Aires: Contratiempo Ediciones.

Machoni SJ, Antonio (1732). Las siete estrellas de la mano de Jesús. Tratado histórico de las admirables vidas y resplandores de virtudes de siete varones ilustres de la Compañía de Jesús, naturales de Cerdeña y misioneros apostólicos de la provincia del Paraguay de la misma Compañía. Córdoba (España): Joseph Santos Balbás.

Maeder, Ernesto J. A. (2001). Los bienes de los jesuitas. Resistencia: Instituto de Investigaciones Geohistóricas-CONICET.

Miranda SI, Francisco Javier (1916). Vida del venerable sacerdote Don Domingo Muriel. Religioso un tiempo de la abolida Compañía de Jesús y último provincial de su provincia del Paraguay. Córdoba: Universidad Nacional de Córdoba.

O’Neill SI, Charles E. y Domínguez SI, Joaquín Mª (2001). Diccionario Histórico de la Compañía de Jesús. Biográfico-Temático. Madrid: Universidad Pontificia de Comillas. T. II.

Page, Carlos A. (1998). La estancia jesuítica de San Ignacio de los Ejercicios. Calamuchita. Córdoba. Córdoba: Junta Provincial de Historia.

-- (2004). El Colegio Máximo de Córdoba (Argentina) según las Cartas Anuas de la Compañía de Jesús. Córdoba: Documentos para la Historia de la Compañía de Jesús en Córdoba.

- (2011). Relatos desde el exilio. Memorias de los jesuitas expulsos de la antigua Provincia del Paraguay. Asunción: Servi Libros.

- (2013). "Las cartas de los generales Tirso González y Miguel Ángel Tamburini para la provincia del Paraguay”. IHS. Antiguos jesuitas en Iberoamérica, Vol.1 $\mathrm{N}^{\mathrm{o}} 1$.

Page, Carlos A. y Schávelzon, Daniel (2012). "Francesc Fábregas i Pujadas, autor del primer relevamiento de la estancia jesuítica de San Ignacio de Calamuchita en Córdoba". Comechingonia virtual. Vol. VI, N² 2 .

Revista de Buenos Aires. Junio 1865. VII: 231. 
Schávelzon, Daniel (2012). Dejá que se caiga solo: de Retiro Espiritual a Cárcel. El edificio de los jesuitas en San Telmo como metáfora del patrimonio porteño. Seminario de Crítica. Instituto de Arte Americano e Investigaciones Estéticas "Mario J. Buschizzo".

Sobron SJ, Dalmacio H. (1997). Giovanni Andrea Bianchi, un arquitecto italiano en los albores de la arquitectura argentina. Buenos Aires: Corregidor.

Storni SI, Hugo (1980). Catálogo de los jesuitas de la Provincia del Paraguay (Cuenca del Plata) 1585-1768. Roma: Institutum Historicum SI. 